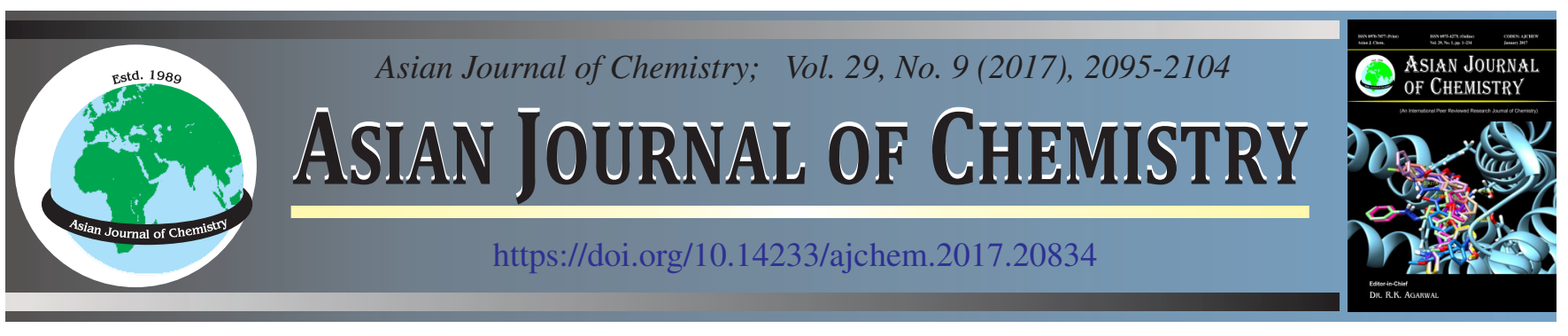

\title{
Activation Energy Parameters for Hydrodynamic Permeability of Binary Aqueous Solutions of Divalent Transition Metal Sulphates and Magnesium Sulphate Through an Inorganic Membrane of Aluminium Oxide
}

\author{
R.C. Thakur ${ }^{1, *}$, Ravi Sharma ${ }^{1}$, Sonika Singh $^{1}$ and M.L. Parmar ${ }^{2}$
}

${ }^{1}$ Department of Chemistry, School of Chemical Engineering \& Physical Sciences, Lovely Professional University, Phagwara-144 411, India ${ }^{2}$ Department of Chemistry, Himachal Pradesh University, Summer Hill, Shimla-171 005, India

*Corresponding author: E-mail: drthakurchem@gmail.com

\begin{abstract}
In the present study, inorganic membranes of aluminium oxide has been used for the determination of hydrodynamic permeabilities of some divalent transition metal sulphates namely; manganese sulphate, cobalt sulphate, nickel sulphate, copper sulphate, zinc sulphate and magnesium sulphate (reference electrolyte) in water. Filtration coefficient $\left(\mathrm{L}_{\mathrm{p}}\right)$ as a function of hydrodynamic pressure and the concentration of the solute, rejection or coupling coefficient $(\sigma)$ as a function of solute concentration and activation parameters in order to know the mechanism of flow across an inorganic membrane of aluminum oxide are also determined.
\end{abstract}

Keywords: Hydrodynamic permeability, Activation parameters, Filtration coefficient, Coupling coefficient.

\section{INTRODUCTION}

When two forces like potential gradient and pressure gradient couple together it gives rise of current flux and volume flux. Similarly when two different phases are brought in contact with each other, electro-kinetic effects like streaming potential [1-4], electrophoresis [5-8], sedimentation potential (Dorn effect) [9-11] and electro-osmosis [12-16] are observed at the interfacial boundary. As a result of these electro kinetic phenomenons electrical double-layer at the interfacial boundary also forms and variety of transport phenomena arise across a membrane when it is subjected to different driving forces [17-19]. Some of these phenomena like ion- migration, electro-osmosis, self-diffusion, hydrodynamic flow, salt filtration, streaming potential and membrane potential, etc. occurring across the ionic membranes which have been described by Spiegler [20]. Blokhra et al. [21-26] have also reported the transport phenomenon of various electrolytes and non-electrolytes across different types of diaphragm using the thermodynamics of irreversible processes. It is expected that the electrical double layer in highly charged membranes would be more sensitive to the change in characteristics depending on the nature of the permeants which would naturally be reflected in transport properties, For better understanding and prediction of a membrane's permeation characteristics, an insight into the structural details, e.g. effective cross-sectional area, equivalent pore radius and the electrical character of the membrane are required. The permeability of any membrane depends upon the molecular size of the permeating fluid, the number of pores of the membrane, the density and viscosity of the permeant, the state of aggregation of the liquid and the number of hydrogen bonds, etc.

\section{EXPERIMENTAL}

Manganese sulphate, cobalt sulphate, nickel sulphate, copper sulphate, zinc sulphate, magnesium sulphate and aluminium oxide of AnalaR grade were used after drying over calcium oxide for more than $24 \mathrm{~h}$. Preparation of the membrane and complete set up of the assembly has already been explained by Thakur et al. [27] (Fig. 1).

\section{RESULTS AND DISCUSSION}

In the present study, the hydrodynamic permeabilties of some divalent transition metal sulphates e.g., manganese sulphate, cobalt sulphate, nickel sulphate, copper sulphate, zinc sulphate and magnesium sulphate in water through an inorganic membrane of aluminum oxide have been determined. The permeability of any membrane depends upon the molecular size of the permeating fluid, the state of aggregation of the liquid, the number of hydrogen bonds, etc. None of the properties explained above determines the nature of any membrane. So, before using any membrane into its practical use, it is important to know its 


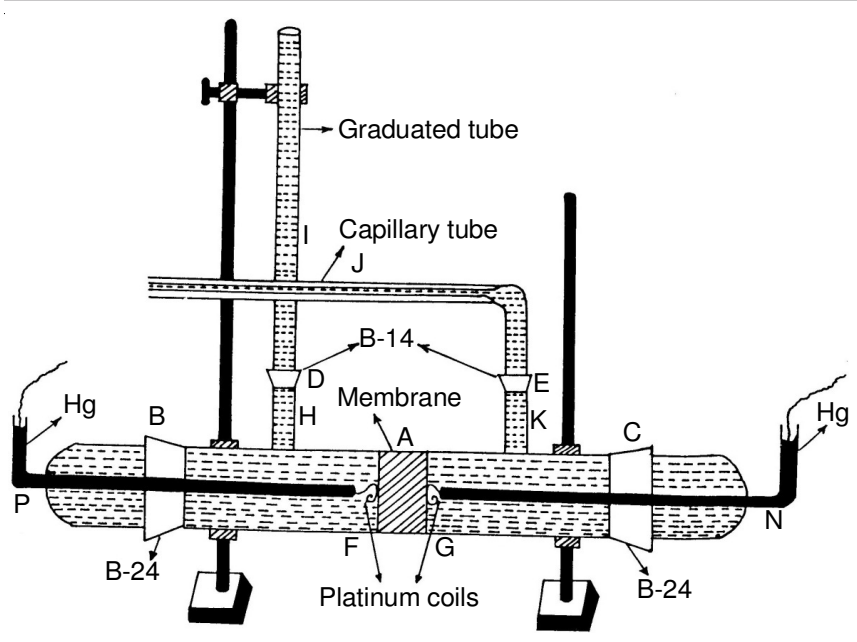

Fig. 1. Schematic set up of the apparatus

characteristics like; effective cross-sectional area, equivalent pore radius and electrical nature of the membrane.

Membrane characterization: The thickness of the inorganic membrane of aluminum oxide was measured with the help of a cathetometer, which measures up to $0.001 \mathrm{~cm}$ and found to be $1.751 \mathrm{~cm}$. The diameter of the membrane was noted with the help of a travelling microscope of $0.001 \mathrm{~cm}$ sensitivity and found to be $1.858 \mathrm{~cm}$.

The rate of permeation through any membrane under the influence of hydrostatic pressure depend upon the effective cross sectional area ' $\mathrm{A}$ ' and the effective length ' 1 ' of the pores of the membrane. An unambiguous determination of either of these quantities is difficult due to complex geometry of the opening with in a membrane. It is, however, possible to deter- mine the ratio ' $\mathrm{A} / 1$ ' the so called membrane constant, in terms of which the permeant behaviour of any membrane can be expressed quantitatively.

For a membrane having ' $n$ ' number of pores of equivalent radius ' $r$ ' the effective cross-sectional area electrical conductance ' $\mathrm{K}$ ' of the membrane equilibrated with a premeant having specified conductance equilibrated with a permeant having specific conductance ' $\mathrm{k}$ ' is given by the following relation [28]:

$$
\mathrm{K}=\mathrm{n} \pi \mathrm{r}^{2} \times \frac{\mathrm{k}}{1}=\frac{\mathrm{A}}{1} \times \mathrm{k}
$$

So that the membrane constant can be written as follows:

$$
\frac{\mathrm{A}}{1}=\mathrm{K} / \mathrm{k}
$$

This constant is characteristics parameter of a membrane and is independent of the nature of permeating fluid, as long as the interaction between the premeant and membrane matrix is not strong enough to alter its equivalent pore radius [29]. The membrane constant thus estimates from the relation (2) for different binary aqueous solution of divalent transition metal sulphates (mentioned above) and magnesium sulphate are given in Table-1.

The perusal of Table- 1 shows that the value of membrane constant (A/1) is fairly constant for all the binary aqueous solution of divalent transition metal sulphates and magnesium sulphate and it is in accordance with the findings of Singh et al. [28]. This clearly proves that membrane constant 'A/1' is a characteristic properly of the membrane only and is independent of the nature of permeating fluid.

The average pore radius of any membrane can be calculated from the following expression:

TABLE-1

MEMBRANE CHARACTERISTICS ASCERTAINED FROM CONDUCTANCE DATA FOR DIFFERENT BINARY AQUEOUS SOLUTION OF MANGANESE SULPHATE, COBALT SULPHATE, NICKEL SULPHATE,

\begin{tabular}{|c|c|c|c|c|c|c|c|}
\hline $\begin{array}{c}\text { Concentration } \\
(\mathrm{m})\end{array}$ & $\begin{array}{l}\mathrm{K} \times 10^{5} \\
\left(\mathrm{Ohm}^{-1}\right)\end{array}$ & $\begin{array}{c}\mathrm{k} \times 10^{5} \\
\left(\mathrm{Ohm}^{-1} \mathrm{~cm}^{-1}\right)\end{array}$ & $\mathrm{A} / 1(\mathrm{~cm})$ & $\begin{array}{c}\text { Concentration } \\
(\mathrm{m})\end{array}$ & $\begin{array}{l}\mathrm{K} \times 10^{5} \\
\left(\mathrm{Ohm}^{-1}\right)\end{array}$ & $\begin{array}{c}\mathrm{k} \times 10^{5} \\
\left(\mathrm{Ohm}^{-1} \mathrm{~cm}^{-1}\right)\end{array}$ & $\mathrm{A} / 1(\mathrm{~cm})$ \\
\hline \multicolumn{4}{|c|}{ Manganese sulphate } & \multicolumn{4}{|c|}{ Copper sulphate } \\
\hline 0.001 & 0.115 & 0.229 & 0.385 & 0.001 & 0.120 & 0.310 & 0.387 \\
\hline 0.003 & 0.225 & 0.579 & 0.388 & 0.003 & 0.218 & 0.557 & 0.385 \\
\hline 0.005 & 0.370 & 0.966 & 0.383 & 0.005 & 0.292 & 0.761 & 0.384 \\
\hline 0.007 & 0.450 & 1.166 & 0.386 & 0.007 & 0.401 & 1.030 & 0.389 \\
\hline 0.010 & 0.585 & 1.527 & 0.382 & 0.010 & 0.648 & 1.659 & 0.391 \\
\hline 0.030 & 0.875 & 2.296 & 0.381 & 0.030 & 0.821 & 2.115 & 0.388 \\
\hline 0.050 & 1.350 & 3.488 & 0.387 & 0.050 & 1.248 & 3.251 & 0.384 \\
\hline \multicolumn{4}{|c|}{ Cobalt sulphate } & \multicolumn{4}{|c|}{ Zinc sulphate } \\
\hline 0.001 & 0.100 & 0.260 & 0.385 & 0.001 & 0.039 & 0.245 & 0.381 \\
\hline 0.003 & 0.221 & 0.583 & 0.387 & 0.003 & 0.183 & 0.479 & 0.383 \\
\hline 0.005 & 0.341 & 0.871 & 0.391 & 0.005 & 0.302 & 0.791 & 0.382 \\
\hline 0.007 & 0.457 & 1.180 & 0.387 & 0.007 & 0.389 & 1.010 & 0.385 \\
\hline 0.010 & 0.658 & 1.713 & 0.384 & 0.010 & 0.632 & 1.645 & 0.382 \\
\hline 0.050 & 1.342 & 3.458 & 0.388 & 0.050 & 1.280 & 3.341 & 0.383 \\
\hline \multicolumn{4}{|c|}{ Nickel sulphate } & \multicolumn{4}{|c|}{ Magnesium sulphate } \\
\hline 0.001 & 0.105 & 0.275 & 0.383 & 0.001 & 0.104 & 0.270 & 0.355 \\
\hline 0.003 & 0.250 & 0.650 & 0.384 & 0.003 & 0.184 & 0480 & 0.385 \\
\hline 0.005 & 0.373 & 0.970 & 0.385 & 0.005 & 0.261 & 0.685 & 0.381 \\
\hline 0.007 & 0.477 & 1.250 & 0.382 & 0.007 & 0.350 & 0.915 & 0.383 \\
\hline 0.010 & 0.580 & 1.499 & 0.387 & 0.010 & 0.679 & 1.754 & 0.387 \\
\hline 0.030 & 0.894 & 2.305 & 0.388 & 0.030 & 0.878 & 2.304 & 0.381 \\
\hline 0.050 & 1.308 & 3.415 & 0.383 & 0.050 & 0.183 & 3.115 & 0.380 \\
\hline
\end{tabular}
COPPER SULPAHTE, ZINC SULPATE AND MAGNESIUM SULPHATE AT $303.15 \mathrm{~K}$ 


$$
\begin{array}{r}
\left(\frac{\mathrm{J}_{\mathrm{v}}}{\Delta \mathrm{P}}\right)_{\Delta \pi=0}=\frac{\mathrm{n} \pi \mathrm{r}^{4}}{8 \eta \mathrm{l}}=\frac{\mathrm{n} \pi \mathrm{r}^{2} \times \mathrm{r}^{2}}{8 \eta \mathrm{l}} \\
=\frac{\mathrm{n} \pi \mathrm{r}^{2}}{1} \times \frac{\mathrm{r}^{2}}{8 \eta}=\frac{\mathrm{A}}{l} \times \frac{\mathrm{r}^{2}}{8 \eta} \\
\mathrm{r}=\left(\frac{8 \eta\left(\frac{\mathrm{J}_{\mathrm{v}}}{\Delta \mathrm{P}}\right)_{\Delta \pi=0}}{\mathrm{~A} / 1}\right)^{1 / 2}
\end{array}
$$

where $\eta$ represents the coefficient of viscosity of the permeating fluid, $\mathbf{J}_{\mathrm{v}}$ the volume flow through the membrane $(\Delta \mathrm{P})$ is the pressure difference across the interface in centimeters of the permeating fluid and $\Delta \pi$ is the osmotic pressure across the membrane.

The values of $\mathbf{J}_{\mathrm{v}}$, volume flow for different concentrations of binary aqueous solutions of manganese sulphate is recorded in Table-2. Same trend has been observed for other transition metal sulphates and magnesium sulphate and are not shown. The values of densities and viscosities required for the calculation of "equivalent pore radius " $r$ " of the membrane, for the different binary aqueous solutions of divalent transition metal sulphates and magnesium sulphate are given in Table- 3 .

The equivalent pore radii, calculated with the help of relation (3) for different binary aqueous solution of divalent transition metal sulphates and magnesium sulphate are shown in Table-4. It is evident from Table-4 that the equivalent pore radius of the membrane decreases with the increase in concentration of individual divalent transition metal sulphate and magnesium sulphate in water at $303.15 \mathrm{~K}$ and this may be attributed to the increase in thickness of electrical double layer at the walls of pores of aluminium oxide membrane. These results suggest that all the divalent transition metal sulphates and magnesium sulphates form cross-links at the walls of the pores of inorganic member of aluminum oxide thereby resulting in the decrease of equivalent pore radius. It is also

TABLE-2

\begin{tabular}{|c|c|c|c|c|c|c|c|}
\hline \multirow{2}{*}{$\begin{array}{c}\Delta \mathrm{P} \times 10^{-4}\left(\text { dyne } \mathrm{cm}^{-2}\right) \\
\text { Concentration of electrolyte } \\
\text { solution }(\mathrm{m})\left(\mathrm{mol} \mathrm{kg}^{-1}\right)\end{array}$} & \multicolumn{7}{|c|}{$\mathrm{J}_{\mathrm{v}} \times 10^{5}\left(\mathrm{~cm} \mathrm{~s}^{-1}\right)$} \\
\hline & 0.001 & 0.003 & 0.005 & 0.007 & 0.010 & 0.030 & 0.050 \\
\hline \multicolumn{8}{|c|}{ Manganese sulphate } \\
\hline 0.49 & 1.45 & 1.40 & 1.30 & 1.25 & 1.20 & 1.15 & 1.10 \\
\hline 0.98 & 2.80 & 2.65 & 2.50 & 2.40 & 2.30 & 2.15 & 2.05 \\
\hline 1.47 & 4.20 & 4.00 & 3.60 & 3.55 & 3.50 & 3.40 & 3.15 \\
\hline 1.96 & 5.65 & 5.30 & 5.10 & 4.90 & 4.65 & 4.40 & 4.15 \\
\hline 2.45 & 6.95 & 6.60 & 6.30 & 6.05 & 5.80 & 5.55 & 5.20 \\
\hline
\end{tabular}

HYDRODYNAMIC VOLUME FLOW $\left(\mathrm{J}_{v}\right)$ FOR DIFFERENT CONCENTRATION OF MANGANESE SULPHATE IN WATER AT DIFFERENT PRESSURES AND AT 303.15 K (PER UNIT AREA OF MEMBRANE)

TABLE-3

DENSITIES, MOLAR VOLUMES AND VISCOSITIES FOR DIFFERENT CONCENTRATIONS OF MANGANESE SULPHATE, COBALT SULPHATE, NICKEL SULPHATE, COPPER SULPHATE, ZINC SULPHATE AND MAGNESIUM SULPHATE IN WATER AT 303.15 K

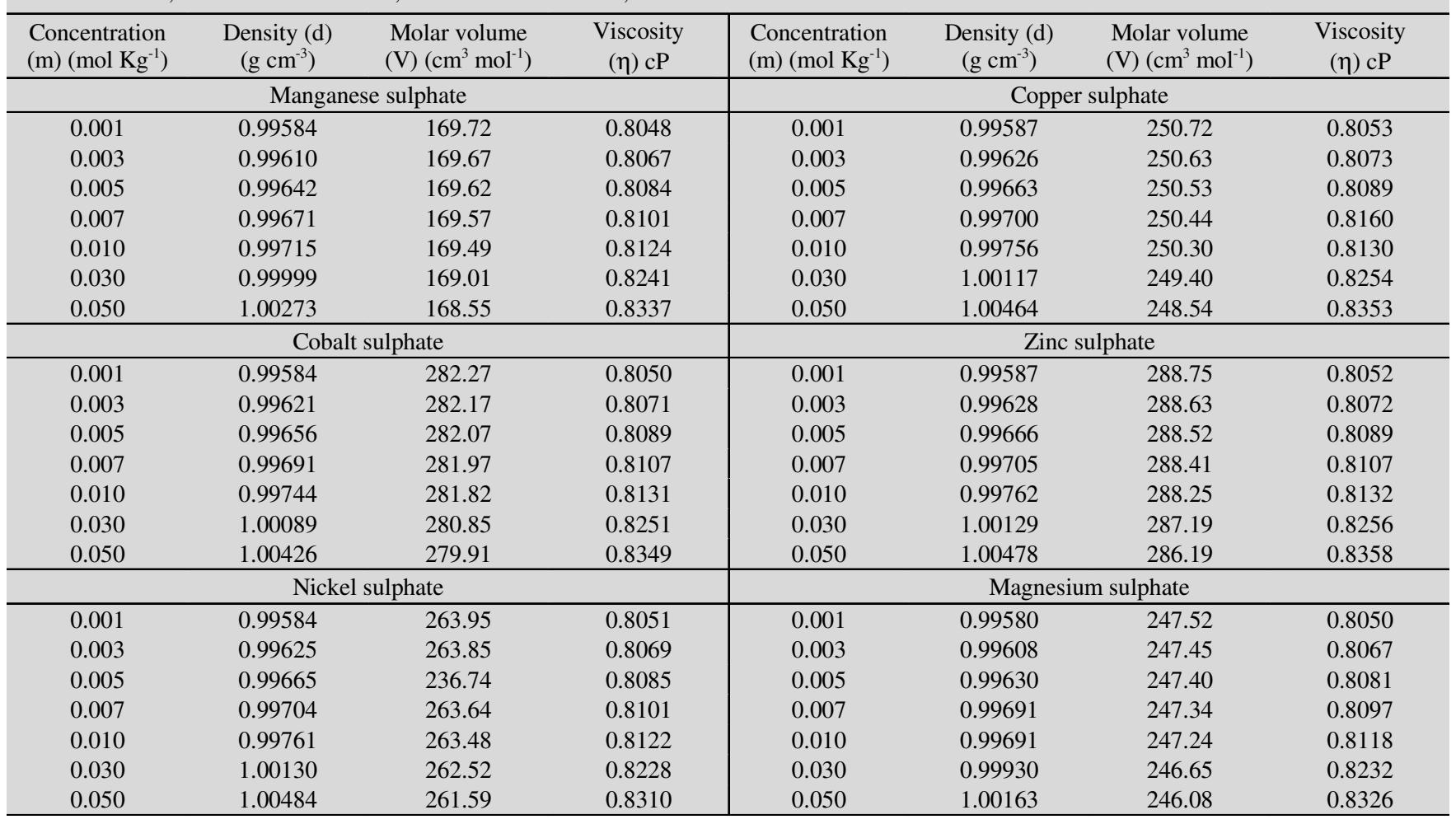




\begin{tabular}{|c|c|c|c|c|c|}
\hline \multicolumn{6}{|c|}{$\begin{array}{l}\text { TABLE-4 } \\
\text { EQUIVALENT PORE RADIUS (r) AND MECHANICAL FILTRATION COEFFICIENT }\left(\mathrm{L}_{\mathrm{p}}\right) \text { FOR DIFFERENT } \\
\text { CONCENTRATIONS OF MANGANESE SULPHATE, COBALT SULPHATE, NICKEL SULPHATE, } \\
\text { COPPER SULPHATE, ZINC SULPHATE AND MAGNESIUM SULPHATE IN WATER AT } 303.15 \mathrm{~K}\end{array}$} \\
\hline $\begin{array}{l}\text { Concentration } \\
(\mathrm{m})\left(\mathrm{mol} \mathrm{Kg}^{-1}\right)\end{array}$ & $\begin{array}{c}\text { Equivalent pore } \\
\text { radius }\left(\mathrm{r} \times 10^{4}\right)(\mathrm{cm})\end{array}$ & $\begin{array}{c}\text { Filtration coefficient } \\
\left(\mathrm{L}_{\mathrm{p}} \times 10^{9}\right)\left(\mathrm{cm}^{3} \mathrm{dy} \mathrm{n}^{-1} \mathrm{~s}^{-1}\right)\end{array}$ & $\begin{array}{l}\text { Concentration }(\mathrm{m}) \\
\left(\mathrm{mol} \mathrm{Kg}^{-1}\right)\end{array}$ & $\begin{array}{c}\text { Equivalent pore } \\
\text { radius }\left(\mathrm{r} \times 10^{4}\right)(\mathrm{cm})\end{array}$ & $\begin{array}{c}\text { Filtration coefficient } \\
\left(\mathrm{L}_{\mathrm{p}} \times 10^{9}\right)\left(\mathrm{cm}^{3} \text { dyne }^{-1} \mathrm{~s}^{-1}\right)\end{array}$ \\
\hline \multicolumn{3}{|c|}{ Manganese sulphate } & \multicolumn{3}{|c|}{ Copper sulphate } \\
\hline 0.001 & 2.18 & 2.65 & 0.001 & 2.08 & 2.61 \\
\hline 0.003 & 2.11 & 2.60 & 0.003 & 2.03 & 2.57 \\
\hline 0.005 & 2.09 & 2.58 & 0.005 & 1.99 & 2.55 \\
\hline 0.007 & 2.04 & 2.56 & 0.007 & 1.94 & 2.49 \\
\hline 0.010 & 2.00 & 2.48 & 0.010 & 1.91 & 2.44 \\
\hline 0.030 & 1.97 & 2.24 & 0.030 & 1.85 & 2.20 \\
\hline 0.050 & 1.91 & 2.05 & 0.050 & 1.83 & 1.76 \\
\hline \multicolumn{3}{|c|}{ Cobalt sulphate } & \multicolumn{3}{|c|}{ Zinc sulphate } \\
\hline 0.001 & 2.15 & 2.35 & 0.001 & 2.06 & 2.51 \\
\hline 0.003 & 2.04 & 2.30 & 0.003 & 1.98 & 2.46 \\
\hline 0.005 & 1.94 & 2.28 & 0.005 & 1.94 & 2.45 \\
\hline 0.007 & 1.92 & 2.29 & 0.007 & 1.89 & 2.42 \\
\hline 0.010 & 1.86 & 2.18 & 0.010 & 1.85 & 2.40 \\
\hline 0.030 & 1.83 & 1.95 & 0.030 & 1.81 & 2.13 \\
\hline 0.050 & 1.79 & 1.70 & 0.050 & 1.80 & 1.87 \\
\hline \multicolumn{3}{|c|}{ Nickel sulphate } & \multicolumn{3}{|c|}{ Magnesium sulphate } \\
\hline 0.001 & 1.98 & 2.35 & 0.001 & 2.06 & 2.55 \\
\hline 0.003 & 1.93 & 2.30 & 0.003 & 2.03 & 2.52 \\
\hline 0.005 & 1.89 & 2.28 & 0.005 & 2.00 & 2.50 \\
\hline 0.007 & 1.86 & 2.26 & 0.007 & 1.95 & 2.45 \\
\hline 0.010 & 1.82 & 2.18 & 0.010 & 1.87 & 2.38 \\
\hline 0.030 & 1.79 & 1.95 & 0.030 & 1.84 & 2.10 \\
\hline 0.050 & 1.76 & 1.79 & 0.050 & 1.81 & 1.95 \\
\hline
\end{tabular}

clear from Table-4 that the equivalent pore radii, for the different binary aqueous solution of manganese sulphate, cobalt sulphate, nickel sulphate, copper sulphate, zinc sulphate and magnesium sulphate are different, therefore, it can be concluded, from these results, that the equivalent pore radius is not the characteristic property of the inorganic membrane of aluminium oxide only, but it is seriously influenced by the nature as well as concentration of the permeating fluid.

Filtration coefficient $\left(\mathbf{L}_{\mathbf{P}}\right)$ : The thermodynamic relation for the volume flow $\left(\mathrm{J}_{\mathrm{v}}\right)$, as a function of applied pressure difference $(\Delta \mathrm{P})$ and the osmotic pressure difference $(\Delta \pi)$ across any membrane is given by the following expression [30].

$$
\mathrm{J}_{\mathrm{v}}=\mathrm{L}_{\mathrm{p}} \Delta \mathrm{P}-\sigma \mathrm{L}_{\mathrm{p}} \Delta \pi
$$

where the symbols have their usual significance.

It is convenient to determine the filtration coefficient, $\mathrm{L}_{\mathrm{p}}$, At $\Delta \pi=0$ i.e. at equal concentrations of the solute on both the sides of membrane so that the above expression (4) can be written as:

$$
\mathrm{L}_{\mathrm{P}}=\left(\frac{\mathrm{J}_{\mathrm{v}}}{\Delta \mathrm{P}}\right)_{\Delta \pi=0}
$$

The values of volume flow $J_{v}$, for the binary aqueous solution of manganese sulphate at $303.15 \mathrm{~K}$ is already been recorded in Table-2. Similar trend has been observed for other transition metal sulphates and magnesium sulphate for the values of $\mathrm{J}_{\mathrm{v}}$.

The above expression (eqn 5) shows that the volume transported per unit area of the membrane per unit time, should vary linearly with the hydrostatic pressure difference $(\Delta \mathrm{P})$, across a membrane. The present experiments showed that volume transported per unit time is linearly proportional to the pressure head for all the binary aqueous solution of divalent transition metal sulphates and magnesium sulphate at $303.15 \mathrm{~K}$. A sample plot, for the different concentrations of manganese sulphate in water at $303.15 \mathrm{~K}$ is shown in Fig. 2.

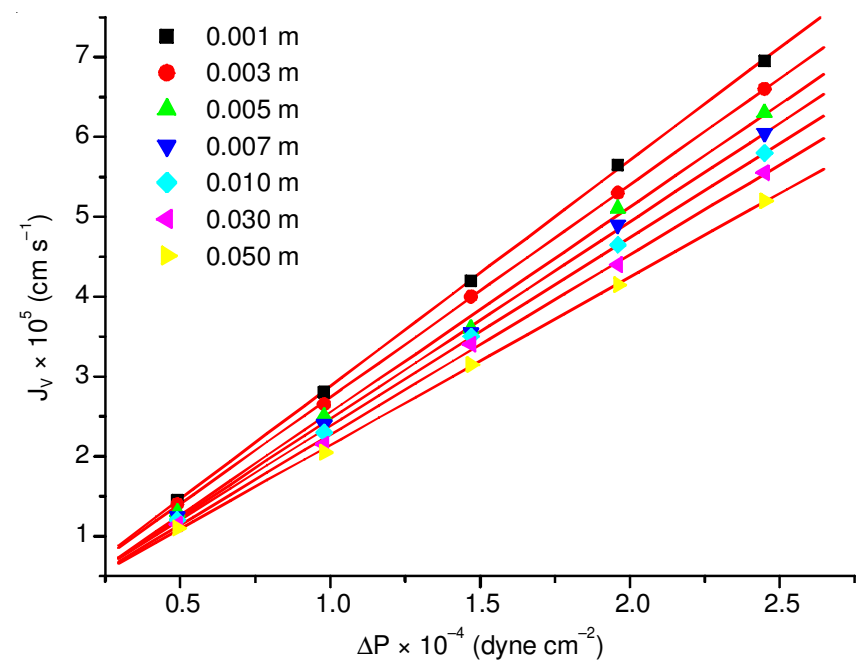

Fig. 2. Plot of $\mathrm{J}_{\mathrm{v}} v s . \Delta \mathrm{P}$ for various concentrations of manganese sulphate in water at $303.15 \mathrm{~K}$

The filteration coefficient, $L_{P}$ has been estimated from the slopes of linear plots of $\mathrm{J}_{\mathrm{v}} v s . \Delta \mathrm{P}$ for the different binary aqueous solutions of divalent transition metal sulphates and magnesium sulphate through the inorganic membrane of aluminum oxide at $303.15 \mathrm{~K}$ and these value are also recorded in Table-4. 
The variation of $L_{P}$ with concentration, for the different binary aqueous solution of divalent transition metal sulphates and magnesium sulphate, is linear. Sample plots for manganese sulphate, cobalt sulphate and zinc sulphate area shown in Fig. 3.

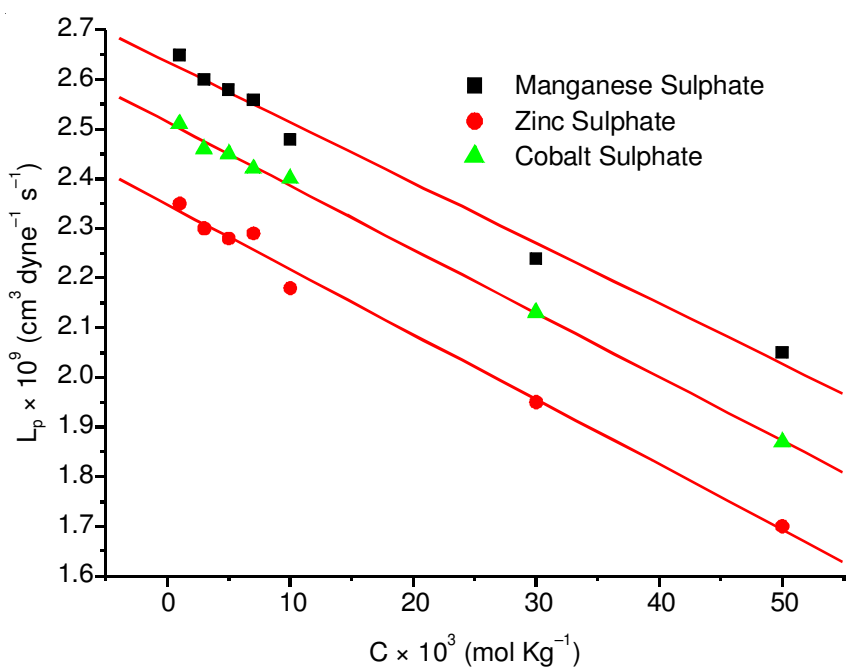

Fig. 3. Plots of $\mathrm{L}_{\mathrm{p}} v s$. concentration for manganese sulphate, cobalt sulphate and zinc sulphate in water at $303.15 \mathrm{~K}$

It is evident from Table-4 (Fig. 3) that $\mathrm{L}_{\mathrm{p}}$ decreases with the increase in concentration of an individual divalent transition metal sulphate and magnesium sulphate in water at $303.15 \mathrm{~K}$ through the inorganic membrane of aluminum oxide. Since $\mathrm{L}_{\mathrm{p}}$ is a constant which expresses the interaction between the membrane matrix and permeating fluid, therefore it may be inferred from these results that the friction between the interfaces of aluminum oxide and permeating fluids increases with the increase in concentration of individual divalent transition metal sulphate and magnesium sulphate in water at $303.15 \mathrm{~K}$. It is also clear form Table-4 that $\mathrm{L}_{\mathrm{P}}$ is different for the different electrolytes, studied here, so it may be concluded from these results that $\mathrm{L}_{P}$ is not the characteristic property of the inorganic interface of aluminium oxide only but it is seriously influenced by the nature of the permeating fluid.

Rejection or coupling coefficient $(\sigma)$ : The thermodynamic relation for the resultant volume flow $\mathbf{J}_{\mathrm{v}}{ }^{\prime}$ as a function of applied pressure difference $\Delta \mathrm{P}^{\prime}$ and the osmotic pressure difference, $\Delta \pi$ through an inorganic membrane of aluminum oxide is given the following expression [30].

$$
\mathrm{J}_{\mathrm{v}}{ }^{\prime}=\mathrm{L}_{\mathrm{P}}{ }^{\prime} \Delta \mathrm{P}^{\prime}-\sigma \mathrm{L}_{\mathrm{P}}{ }^{\prime} \Delta \pi
$$

$$
\text { Or } \quad \mathrm{J}_{\mathrm{v}}{ }^{\prime}=\mathrm{L}_{\mathrm{P}}{ }^{\prime}\left[\Delta \mathrm{P}^{\prime}-\sigma \Delta \pi\right]
$$

here $\sigma$ is known as rejection/coupling coefficient or membrane selectivity and the other symbols have their usual signification. Since $\Delta \pi=\mathrm{RT} \Delta \mathrm{C}$, therefore the above expression (7) may also be written as follows:

$$
\mathrm{J}_{\mathrm{v}}{ }^{\prime}=\mathrm{LP}_{\mathrm{P}}{ }^{\prime}\left[\Delta \mathrm{P}^{\prime}-\sigma \mathrm{RT} \Delta \mathrm{C}\right]
$$

where $\mathrm{J}_{\mathrm{v}}{ }^{\prime}$ is the net or resultant volume flow, $\mathrm{R}$ is the gas constant, $\mathrm{T}$ is the absolute temperature and $\Delta \mathrm{C}$ is the concentration difference across the inorganic membrane of aluminium oxide. The values of the resultant volume flow $\mathbf{J}_{\mathrm{v}}{ }^{\prime}$ for various concentration differences across the inorganic membrane of aluminum oxide for magnesium sulphate at 303.15 $\mathrm{K}$ is given in Table-5.

Similar trend has been observed for all the transition metal sulphates and data is not shown in the mauscript. According to relation (8) the plot of $\mathrm{J}_{\mathrm{v}}{ }^{\prime} v s . \Delta \mathrm{P}^{\prime}$ should be linear and the same has been found to be true in case of all the divalent transition metal sulphates and magnesium sulphates in water at $303.15 \mathrm{~K}$. A sample plot is shown in Fig. 4 for magnesium sulphate in water at $303.15 \mathrm{~K}$.

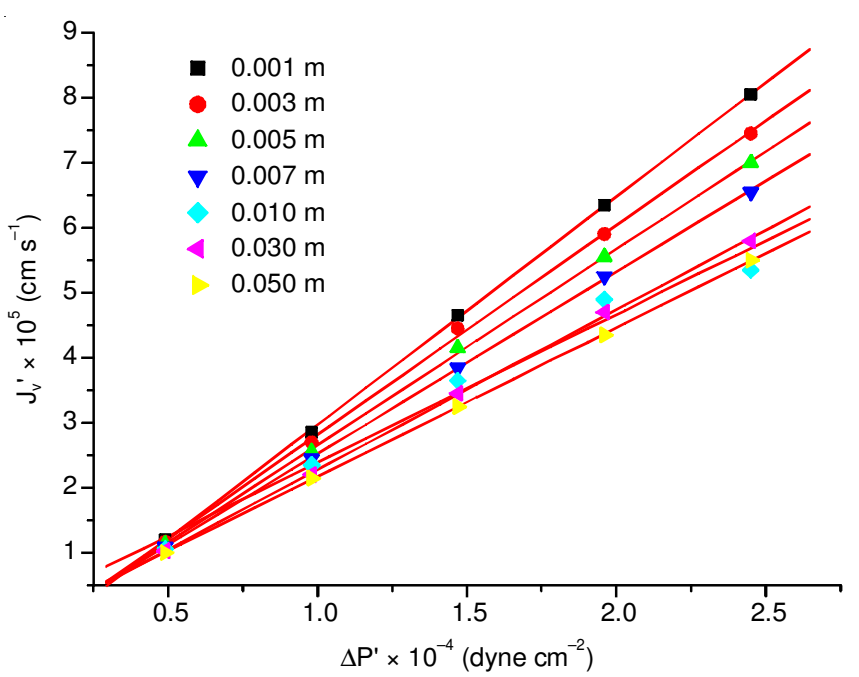

Fig. 4. Plot of $\mathrm{J}_{\mathrm{v}}$ ' $v s$. $\Delta \mathrm{P}$ ' for various concentrations of magnesium sulphate in water at $303.15 \mathrm{~K}$

The filtration coefficient $L_{P}^{\prime}$ and $\left(J_{v}{ }^{\prime}\right)_{\Delta p^{\prime}=0}$ have been computed by the least squares fit to the slope and intercepts of the straight line plot of $\mathrm{J}_{\mathrm{v}}{ }^{\prime} v s . \Delta \mathrm{P}^{\prime}$ respectively and these values have been recorded in Table- 6 .

\begin{tabular}{|c|c|c|c|c|c|c|c|}
\hline \multicolumn{8}{|c|}{$\begin{array}{l}\text { TABLE-5 } \\
\text { RESULTANT VOLUME FLOW J' } \\
\text { FOR DIFFERENT CONCENTRATIONS OF MAGNESIUM SULPHATE IN WATER AT } 303.15 \mathrm{~K}\end{array}$} \\
\hline$\Delta \mathrm{P}^{\prime} \times 10^{-4}\left(\right.$ dyne $\left.\mathrm{cm}^{-2}\right)$ & & & & $10^{5}(\mathrm{cn}$ & & & \\
\hline $\begin{array}{l}\text { Concentration of electrolyte } \\
\text { solution }(\mathrm{m})\left(\mathrm{mol} \mathrm{Kg}^{-1}\right)\end{array}$ & 0.001 & 0.003 & 0.005 & 0.007 & 0.010 & 0.030 & 0.050 \\
\hline \multicolumn{8}{|c|}{ Magnesium sulphate } \\
\hline 0.49 & 1.20 & 1.17 & 1.13 & 1.09 & 1.06 & 1.03 & 1.00 \\
\hline 0.98 & 2.85 & 2.70 & 2.55 & 2.45 & 2.35 & 2.20 & 2.15 \\
\hline 1.47 & 4.65 & 4.45 & 4.15 & 3.85 & 3.65 & 3.45 & 3.25 \\
\hline 1.96 & 6.35 & 5.90 & 5.55 & 5.25 & 4.90 & 4.70 & 4.35 \\
\hline 2.45 & 8.05 & 7.45 & 7.00 & 6.55 & 6.35 & 5.80 & 5.50 \\
\hline
\end{tabular}

It is evident from Table- 6 that the values of $L_{P}^{\prime}$ and $\left(J_{V}{ }^{\prime}\right)_{\triangle P^{\prime}=0}$ are different for various concentrations of an individual solute 
TABLE-6

RESULTANT VOLUME FLOW $\left(\mathrm{J}_{\mathrm{V}}{ }^{\prime}\right)_{\triangle \mathrm{P}=0}$, MECHANICAL FILTRATION COEFFICIENT, $\mathrm{L}_{\mathrm{P}}{ }^{\prime},($ FOR THE DETERMINATION OF REJECTION COEFFICIENT) AND REJECTION COEFFICIENT, $\sigma$, FOR MANGANESE SULPHATE, COBALT SULPHATE, NICKEL SULPHATE, COPPER SULPHATE, ZINC SULPHATE AND MAGNESIUM SULPHATE IN WATER AT 303.15

\begin{tabular}{|c|c|c|c|c|c|c|c|}
\hline $\begin{array}{l}\text { Concentration } \\
(\mathrm{m})\left(\mathrm{mol} \mathrm{kg}^{-1}\right) \\
\end{array}$ & $\begin{array}{c}\left(\mathrm{J}_{\mathrm{V}}{ }^{\prime}\right)_{\Delta_{\mathrm{p}=0}} \times 10^{5} \\
\left(\mathrm{~cm} \mathrm{~s}^{-1}\right)\end{array}$ & $\begin{array}{c}\mathrm{L}_{\mathrm{p}}{ }^{\prime} \times 10^{9} \\
\left(\mathrm{~cm}^{3} \text { dyne }^{-1} \mathrm{~s}^{-1}\right) \\
\end{array}$ & $\sigma \times 10^{6}$ & $\begin{array}{l}\text { Concentration } \\
(\mathrm{m})\left(\mathrm{mol} \mathrm{kg}^{-1}\right) \\
\end{array}$ & $\begin{array}{c}\left(\mathrm{J}_{\mathrm{V}}\right)_{\Delta_{\mathrm{p}=0}} \times 10^{5} \\
\left(\mathrm{~cm} \mathrm{~s}^{-1}\right)\end{array}$ & $\begin{array}{c}\mathrm{L}_{\mathrm{p}}{ }^{\prime} \times 10^{9} \\
\left(\mathrm{~cm}^{3} \text { dyne }^{-1} \mathrm{~s}^{-1}\right) \\
\end{array}$ & $\sigma \times 10^{6}$ \\
\hline \multicolumn{4}{|c|}{ Manganese sulphates } & \multicolumn{4}{|c|}{ Copper sulphates } \\
\hline 0.001 & -0.403 & 3.340 & 4.787 & 0.001 & -0.444 & 3.402 & 5.178 \\
\hline 0.003 & -0.366 & 3.066 & 1.579 & 0.003 & -0.304 & 3.070 & 1.310 \\
\hline 0.005 & -0.260 & 2.809 & 0.734 & 0.005 & -0.225 & 2.820 & 0.633 \\
\hline 0.007 & -0.172 & 2.621 & 0.372 & 0.007 & -0.191 & 2.641 & 0.410 \\
\hline 0.010 & -0.145 & 2.540 & 0.226 & 0.010 & -0.122 & 2.453 & 0.197 \\
\hline 0.030 & -0.120 & 2.435 & 0.065 & 0.030 & -0.084 & 2.285 & 0.049 \\
\hline 0.050 & -0.105 & 2.285 & 0.039 & 0.050 & -0.048 & 2.172 & 0.017 \\
\hline \multicolumn{4}{|c|}{ Cobalt sulphates } & \multicolumn{4}{|c|}{ Zinc sulphates } \\
\hline 0.001 & -0.480 & 3.471 & 5.486 & 0.001 & -0.621 & 3.680 & 6.704 \\
\hline 0.003 & -0.365 & 3.158 & 1.528 & 0.003 & -0.531 & 3.468 & 2.023 \\
\hline 0.005 & -0.317 & 2.918 & 0.862 & 0.005 & -0.392 & 3.178 & 0.979 \\
\hline 0.007 & -0.254 & 2.699 & 0.533 & 0.007 & -0.333 & 3.010 & 0.627 \\
\hline 0.010 & -0.183 & 2.535 & 0.286 & 0.010 & -0.264 & 2.842 & 0.368 \\
\hline 0.030 & -0.174 & 2.367 & 0.097 & 0.030 & -0.200 & 2.664 & 0.099 \\
\hline 0.050 & -0.165 & 2.368 & 0.055 & 0.050 & -0.136 & 2.529 & 0.043 \\
\hline \multicolumn{4}{|c|}{ Nickel sulphates } & \multicolumn{4}{|c|}{ Magnesium sulphates } \\
\hline 0.001 & -0.357 & 3.043 & 4.653 & 0.001 & -0.554 & 3.525 & 6.235 \\
\hline 0.003 & -0.235 & 2.758 & 1.127 & 0.003 & -0.407 & 3.230 & 1.673 \\
\hline 0.005 & -0.147 & 2.504 & 0.466 & 0.005 & -0.358 & 3.021 & 0.940 \\
\hline 0.007 & -0.125 & 2.428 & 0.292 & 0.007 & -0.289 & 2.812 & 0.582 \\
\hline 0.010 & -0.098 & 2.318 & 0.167 & 0.010 & -0.287 & 2.690 & 0.423 \\
\hline 0.030 & -0.086 & 2.225 & 0.051 & 0.030 & -0.186 & 2.467 & 0.093 \\
\hline 0.050 & -0.074 & 1.865 & 0.031 & 0.050 & -0.119 & 2.295 & 0.041 \\
\hline
\end{tabular}

in water at $303.15 \mathrm{~K}$. Now, if the hydrostatic pressure, across the inorganic membrane of aluminum oxide, is kept constant i.e. $\Delta \mathrm{P}^{\prime}=0$ then the above relation (8) can be written as follows:

$$
\begin{aligned}
& \left(\mathrm{J}_{\mathrm{v}}^{\prime}\right)_{\Delta \mathrm{P}^{\prime}=0}=-\sigma \mathrm{L}_{\mathrm{P}}^{\prime}[\mathrm{RT} \Delta \mathrm{C}] \\
& \sigma=-\left[\mathrm{J}_{\mathrm{v}}^{\prime} / \mathrm{L}_{\mathrm{P}}^{\prime} \mathrm{RT} \Delta \mathrm{C}\right]_{\Delta \mathrm{P}^{\prime}=0}
\end{aligned}
$$

here the negative sign indicates that the hydrostatic and osmotic pressures act in opposite direction to each other. The values of rejection coefficient, $\sigma$, can be calculated from relation (9).

All these values of $\sigma$ calculated for the solution of manganese sulphate, cobalt sulphate, nickel sulphate, copper sulphate, zinc sulphate and magnesium sulphate in water at 303.15 K are also recorded in Table- 6 .

The rejection coefficient, $\sigma$ is a measure of membrane selectivity according of Staverman [31] when $\sigma=1$, whole of solute is rejected by a membrane, while $\sigma<1$ means a part of the solute passes through a membrane. $\sigma$ can also be interpreted in term of velocity of the solute as described below:

When $\sigma=1$, velocity of the solute is zero, which means that the solute cannot pass through the membrane. When $\sigma=$ 0 , the solute and solvent flow with equal velocity through the membrane. According to the pore model [32] of transport of solution through a membrane, the rejection coefficient is also known as coupling coefficient and measures the coupling between total volume flux and solute transmission. As the values of $\sigma$ goes towards zero, the coupling between two processes increases and when it becomes equal to zero, the coupling is complete, which means that the solute and solvent flow with equal velocities. This is possible only when solute is identical with the solvent.
It is clear from Table- 6 that the values of $\sigma$ for different binary aqueous solutions of divalent transition metal sulphates and magnesium sulphate decreases with increase in the concentration of each salt at $303.15 \mathrm{~K}$. It means that $\sigma$ reaches to zero as the concentration of each salt increases thereby indicating that the coupling between the above processes increases with the increase in the concentration of each salt and hence solute and solvent flow with almost same velocity only at higher concentration. Further, it is also clear from Table6 that value of $\sigma$ is very small and are further decreases with the increase in concentration difference of a particular solute in water at $303.15 \mathrm{~K}$, thereby indicating that there is no rejection of the solute by the inorganic membrane of aluminium oxide.

Activation parameters: The hydrodynamic permeability of the permeating fluids through porous media, due to pressure gradient, varies exponentially [33] with temperature. The dependence of flow on the temperature is characterized in term of activation energy. In order to obtain activation energy and hence free energy, the hydrodynamic permeability's for different solution of divalent transition metal sulphates viz.; manganese sulphate, cobalt sulphate, nickel sulphate, copper sulphate and zinc sulphate and magnesium sulphate in water have been determined at different temperature $(298.15,303.15$, $308.15,313.15$ and $318.15 \mathrm{~K}$ ). The value of volume flow ' $\mathrm{J}_{\mathrm{v}}$ ' per unit area of the membrane, for the different solutions of cobalt sulphate is given in Table-7. Similar trends have been observed for other transition metal sulphates and magnesium sulphate.

The variation of volume flow ' $\mathrm{J}_{\mathrm{v}}$ ' with pressure difference $\Delta \mathrm{P}$, for a particular solute in particular solvent (i.e. in both 


\begin{tabular}{|c|c|c|c|c|c|c|c|}
\hline \multicolumn{8}{|c|}{$\begin{array}{l}\text { TABLE-7 } \\
\text { HYDRODYNAMIC VOLUME FLOW J J FOR DIFFERENT CONCENTRATION OF } \\
\text { COBALT SULPHATE IN WATER AT DIFFERENT PRESSURE AND TEMPERATURE }\end{array}$} \\
\hline \multirow{2}{*}{$\begin{array}{l}\Delta \mathrm{P}^{\prime} \times 10^{-4}\left(\text { dyne } \mathrm{cm}^{-2}\right) \\
\text { Concentration of electrolyte } \\
\text { solution }(\mathrm{m})\left(\mathrm{mol} \mathrm{Kg}^{-1}\right)\end{array}$} & \multicolumn{7}{|c|}{$\mathrm{J}_{\mathrm{v}} \times 10^{5}\left(\mathrm{~cm} \mathrm{~s}^{-1}\right)$} \\
\hline & 0.001 & 0.003 & 0.005 & 0.007 & 0.010 & 0.030 & 0.050 \\
\hline \multicolumn{8}{|c|}{ Temperature $=298.15 \mathrm{~K}$} \\
\hline 0.49 & 1.40 & 1.35 & 1.20 & 1.15 & 1.10 & 1.05 & 1.00 \\
\hline 0.98 & 2.70 & 2.50 & 2.35 & 2.25 & 2.05 & 1.90 & 1.75 \\
\hline 1.47 & 4.05 & 3.80 & 3.55 & 3.30 & 3.10 & 2.85 & 2.70 \\
\hline 1.96 & 5.45 & 5.00 & 4.70 & 4.40 & 4.10 & 3.80 & 3.55 \\
\hline 2.45 & 6.60 & 6.25 & 5.80 & 5.45 & 5.10 & 4.75 & 4.35 \\
\hline \multicolumn{8}{|c|}{ Temperature $=303.15 \mathrm{~K}$} \\
\hline 0.49 & 1.35 & 1.30 & 1.25 & 1.18 & 1.10 & 1.05 & 0.95 \\
\hline 0.98 & 2.66 & 2.51 & 2.42 & 2.25 & 2.20 & 2.10 & 2.03 \\
\hline 1.47 & 4.00 & 3.85 & 3.63 & 3.50 & 3.35 & 3.20 & 3.10 \\
\hline 1.96 & 5.36 & 5.10 & 4.80 & 4.65 & 4.45 & 4.26 & 4.10 \\
\hline 2.45 & 6.66 & 6.32 & 6.00 & 5.75 & 5.52 & 5.30 & 5.10 \\
\hline \multicolumn{8}{|c|}{ Temperature $=308.15 \mathrm{~K}$} \\
\hline 0.49 & 1.50 & 1.45 & 1.35 & 1.25 & 1.15 & 1.10 & 1.05 \\
\hline 0.98 & 3.00 & 2.80 & 2.60 & 2.50 & 2.30 & 2.15 & 2.05 \\
\hline 1.47 & 4.45 & 4.20 & 4.00 & 3.70 & 3.55 & 3.30 & 3.10 \\
\hline 1.96 & 5.95 & 5.55 & 5.25 & 4.95 & 4.70 & 4.40 & 4.10 \\
\hline 2.45 & 7.30 & 6.85 & 6.50 & 6.20 & 5.85 & 5.50 & 5.15 \\
\hline \multicolumn{8}{|c|}{ Temperature $=313.15 \mathrm{~K}$} \\
\hline 0.49 & 1.55 & 1.50 & 1.45 & 1.31 & 1.20 & 1.12 & 1.01 \\
\hline 0.98 & 3.10 & 2.90 & 2.75 & 2.52 & 2.35 & 2.18 & 2.05 \\
\hline 1.47 & 4.73 & 4.48 & 4.20 & 3.85 & 3.53 & 3.30 & 3.08 \\
\hline 1.96 & 6.24 & 5.82 & 5.50 & 5.00 & 4.73 & 4.38 & 4.12 \\
\hline 7.76 & 7.76 & 7.26 & 6.76 & 6.28 & 5.85 & 5.50 & 5.10 \\
\hline \multicolumn{8}{|c|}{ Temperature $=318.15 \mathrm{~K}$} \\
\hline 0.49 & 1.65 & 1.60 & 1.50 & 1.45 & 1.35 & 4.25 & 1.15 \\
\hline 0.98 & 3.30 & 3.10 & 2.90 & 2.70 & 2.50 & 2.30 & 2.20 \\
\hline 1.47 & 5.00 & 4.65 & 4.35 & 4.10 & 3.73 & 3.56 & 3.30 \\
\hline 1.96 & 6.60 & 6.15 & 5.75 & 5.45 & 5.05 & 4.70 & 4.30 \\
\hline 2.45 & 8.25 & 7.68 & 7.20 & 6.75 & 6.25 & 5.80 & 5.40 \\
\hline
\end{tabular}

binary and ternary system) at different temperature have been found to be linear. Simple plots of $\mathrm{J}_{\mathrm{v}} v s$. $\Delta \mathrm{P}$ for cobalt sulphate in water at $313.15 \mathrm{~K}$ is shown in Fig. 5.

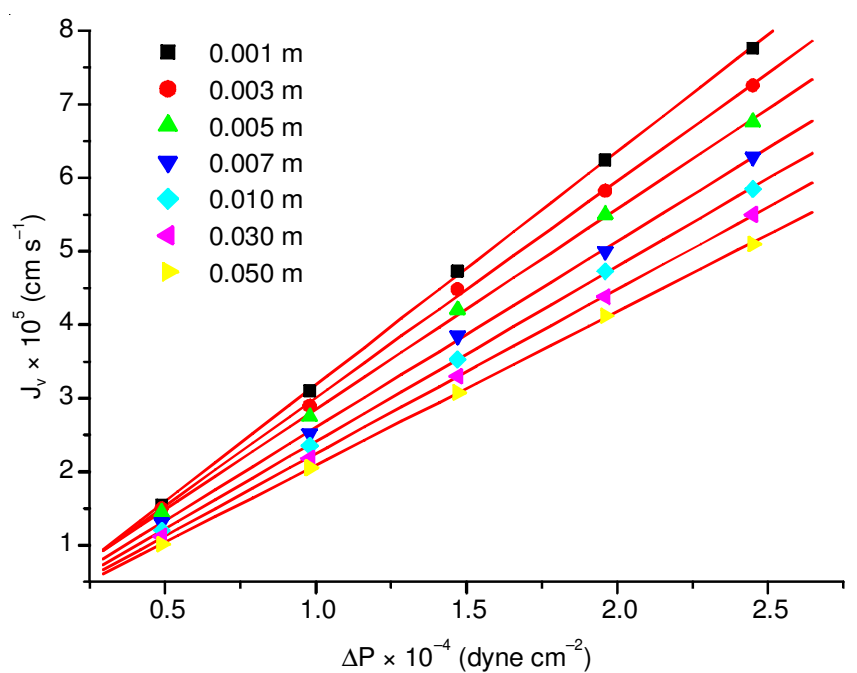

Fig. 5. Plot of $\mathrm{J}_{\mathrm{v}}$ vs. $\Delta \mathrm{P}$ for various concentrations of cobalt sulphate in water at $313.15 \mathrm{~K}$

The values of $\mathrm{L}_{\mathrm{p}}$ have been obtained by the least squares method applied to the slopes of linear pots of $\mathrm{J}_{\mathrm{v}} v s . \Delta \mathrm{P}$ and the corresponding values of the permeability coefficient ' $\mathrm{L}_{\mathrm{p}}$ ' have been recorded in Table- 8 for binary system. The compatibility of relation (10) given below:

$$
\left(\mathrm{J}_{\mathrm{v}}\right)_{\Delta \pi=0}=\mathrm{L}_{\mathrm{P}} \Delta \mathrm{P}
$$

With the Poissuille's law requires that

$$
\mathrm{L}_{\mathrm{P}}=\pi \sum_{\mathrm{i}=1}^{\mathrm{i}=\mathrm{n}} \mathrm{r}_{\mathrm{i}}^{4} / 8 \eta 1
$$

Here ' $r$ ' represent the radius of the $i^{\text {th }}$ capillary, ' $n$ ' the number of capillaries or pores in the membrane matrix, ' $\eta$ ' is the coefficient of viscosity of the permeating fluid and ' 1 ' is the thickness of membrane. The variation of viscosity of fluid with temperature can be expressed as an activation process:

$$
\eta=\mathrm{Ae}^{-\mathrm{En}} / \mathrm{RT}
$$

where ' $\mathrm{A}$ ' is a constant, 'En' the activation energy.

Now substituting relation (12) in (11) and taking logarithm, it is found that:

$$
\begin{gathered}
\log \mathrm{L}_{\mathrm{P}}=\mathrm{K}-\mathrm{E}_{\mathrm{n}} / \mathrm{RT} \\
\mathrm{K}=\log \pi \sum_{\mathrm{i}=1}^{\mathrm{i}=\mathrm{n}} \mathrm{r}_{\mathrm{i}}^{4} / 8 \eta \mathrm{l}=\mathrm{constant}
\end{gathered}
$$

The values of $\log \mathrm{L}_{\mathrm{p}}$ for the different binary in water at different temperatures are given in Table-8. According to relation (13) when $\log \mathrm{L}_{\mathrm{p}}$ is plotted as a function of $1 / \mathrm{T}$, a 
TABLE-8

MECHANICAL FILTRATION COEFFICIENT ' $L_{\mathrm{P}}$ ' FOR DIFFERENT CONCENTRATIONS OF

MANGANESE SULPHATE, COBALT SULPHATE, NICKEL SULPHATE, COPPER SULPHATE,

ZINC SULPHATE AND MAGNESIUM SULPHATE IN WATER AT DIFFERENT TEMPERATURES

\begin{tabular}{|c|c|c|c|c|c|c|c|c|c|c|c|}
\hline \multirow{2}{*}{$\begin{array}{l}\text { Conc. } \\
\text { (m) (mol } \\
\left.\mathrm{kg}^{-1}\right)\end{array}$} & \multicolumn{5}{|c|}{$\mathrm{L}_{\mathrm{p}} \times 10^{9}\left(\mathrm{~cm}^{3}\right.$ dyne $\left.^{-1} \mathrm{~s}^{-1}\right)$} & \multirow{2}{*}{$\begin{array}{l}\text { Conc. } \\
\text { (m) (mol } \\
\left.\mathrm{kg}^{-1}\right)\end{array}$} & \multicolumn{5}{|c|}{$\mathrm{L}_{\mathrm{p}} \times 10^{9}\left(\mathrm{~cm}^{3}\right.$ dyne $\left.^{-1} \mathrm{~s}^{-1}\right)$} \\
\hline & $298.15 \mathrm{~K}$ & $303.15 \mathrm{~K}$ & $308.15 \mathrm{~K}$ & $313.15 \mathrm{~K}$ & $318.15 \mathrm{~K}$ & & $298.15 \mathrm{~K}$ & $303.15 \mathrm{~K}$ & $308.15 \mathrm{~K}$ & $313.15 \mathrm{~K}$ & $318.15 \mathrm{~K}$ \\
\hline \multicolumn{6}{|c|}{ Manganese sulphate } & \multicolumn{6}{|c|}{ Copper sulphate } \\
\hline 0.001 & 2.694 & 2.838 & 2.949 & 3.041 & 3.204 & 0.001 & 2.357 & 2.613 & 2.704 & 2.898 & 3.102 \\
\hline 0.003 & 2.469 & 2.674 & 2.735 & 2.949 & 3.040 & 0.003 & 2.225 & 2.479 & 2.561 & 2.745 & 5.939 \\
\hline 0.005 & 2.304 & 2.585 & 2.600 & 2.775 & 2.908 & 0.005 & 2.102 & 2.356 & 2.429 & 2.633 & 2.749 \\
\hline 0.007 & 2.131 & 2.480 & 2.435 & 2.561 & 2.734 & 0.007 & 1.969 & 2.254 & 2.276 & 2.500 & 2.581 \\
\hline 0.030 & 1.816 & 2.240 & 2.173 & 2.247 & 2.429 & 0.030 & 1.694 & 2.016 & 2.010 & 2.245 & 2.276 \\
\hline 0.050 & 1.645 & 2.111 & 2.098 & 2.102 & 2.346 & 0.050 & 1.633 & 1.934 & 1.865 & 2.071 & 2.149 \\
\hline \multicolumn{6}{|c|}{ Cobalt sulphate } & \multicolumn{6}{|c|}{ Zinc sulphate } \\
\hline 0.001 & 2.684 & 2.766 & 2.969 & 3.175 & 3.367 & 0.001 & 2.337 & 2.510 & 2.632 & 2.816 & 2.939 \\
\hline 0.003 & 2.510 & 2.479 & 2.65 & 2.946 & 3.104 & 0.003 & 2.174 & 2.346 & 2.469 & 2.642 & 2.765 \\
\hline 0.005 & 2.357 & 2.285 & 2.642 & 2.729 & 2.908 & 0.005 & 2.071 & 2.233 & 2.347 & 2.510 & 2.592 \\
\hline 0.007 & 2.193 & 2.203 & 2.520 & 2.535 & 2.725 & 0.007 & 1.949 & 2.008 & 2.081 & 2.184 & 2.274 \\
\hline 0.010 & 2.051 & 2.059 & 5.408 & 2.384 & 2.520 & 0.010 & 1.967 & 2.008 & 2.081 & 2.184 & 2.274 \\
\hline 0.050 & 1.755 & 1.873 & 2.091 & 2.092 & 2.163 & 0.050 & 1.541 & 1.864 & 1.918 & 2.000 & 2.040 \\
\hline \multicolumn{6}{|c|}{ Nickel sulphate } & \multicolumn{6}{|c|}{ Magnesium sulphate } \\
\hline 0.001 & 20239 & 2.346 & 2.388 & 2.837 & 2.980 & 0.001 & 2.327 & 2.551 & 2.582 & 2.743 & 2.888 \\
\hline 0.003 & 2.092 & 2.234 & 2.500 & 2.654 & 2.745 & 0.003 & 2.174 & 2.438 & 2.433 & 2.694 & 2.725 \\
\hline 0.005 & 1.949 & 2.131 & 2.357 & 2.490 & 2.582 & 0.005 & 2.020 & 2.345 & 2.306 & 2.384 & 2.612 \\
\hline 0.007 & 1.927 & 2.059 & 2.327 & 2.337 & 2.439 & 0.007 & 1.929 & 2.254 & 2.081 & 2.312 & 2.469 \\
\hline 0.010 & 1.718 & 1.977 & 2.035 & 2.225 & 2.316 & 0.010 & 1.796 & 2.151 & 1.990 & 2.159 & 2.337 \\
\hline 0.030 & 1.516 & 1.895 & 1.918 & 2.071 & 2.235 & 0.030 & 1.704 & 2.100 & 1.857 & 20.20 & 2.174 \\
\hline 0.050 & 1.327 & 1.793 & 1.937 & 1.918 & 2.045 & 0.050 & 1.561 & 2.049 & 1.704 & 1.936 & 1.990 \\
\hline
\end{tabular}

straight line should be obtained and the same has been found to be true for the various solutions of divalent transition metal sulphates and magnesium sulphate in binary systems. Sample plot of $\log \mathrm{L}_{\mathrm{p}} v s .1 / \mathrm{T}$ for different concentrations of magnesium sulphates in water is given in Fig. 6.

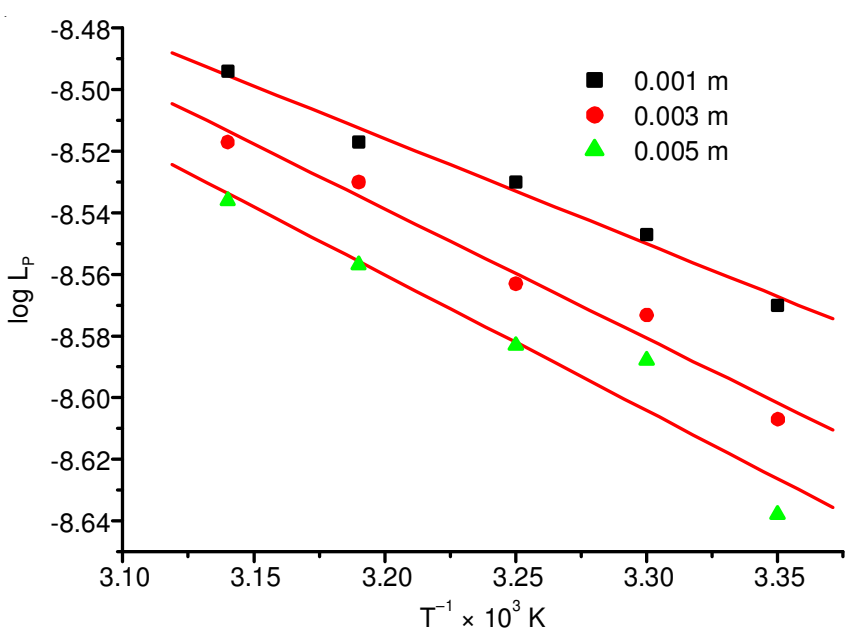

Fig. 6. Plot of $\log \mathrm{L}_{\mathrm{p}}$ vs. 1/T for mangnese sulphate in water

The slope of straight line plot of $\log \mathrm{L}_{\mathrm{p}} v s$. 1/T gives the value of activation energy ' $E_{n}$ ', the $E_{n}$ values have been obtained by applying the least square method to the linear plots of log $\mathrm{L}_{\mathrm{p}} v s .1 / \mathrm{T}$. The values thus obtained, for different solutions of binary systems, have been taken as an enthalpy $\left(\mathrm{E}_{\mathrm{n}}=\Delta \mathrm{H}^{*}\right)$ for the viscous flow of permeating fluid through the inorganic membrane of aluminium oxide. The values of $\Delta \mathbf{H}^{*}$, for different binary aqueous solutions are given in Table-9.
Now using standard Eyring equation [33] given below:

$$
\eta=\frac{\mathrm{Nh}}{\mathrm{V}} \exp \cdot\left(\frac{-\Delta \mathrm{S}^{*}}{\mathrm{R}}\right) \exp \cdot\left(\frac{-\Delta \mathrm{H}^{*}}{\mathrm{RT}}\right)
$$

where ' $\eta$ ' is the viscosity of a permeating fluid, ' $N$ ' Avogadro's number, ' $h$ ' plank's constant, ' $V$ ' the molar volume of the permeating fluid and $\Delta \mathrm{H}^{*}$ the enthalpy of activation. The entropy of activation $\left(\Delta \mathrm{S}^{*}\right)$ can be rearranged as follows:

$$
\Delta \mathrm{S}^{*}=\frac{\Delta \mathrm{H}^{*}}{\mathrm{~T}}+\mathrm{R} \log [\mathrm{Nh} / \mathrm{v} \eta]
$$

The value of densities, viscosities and molar volume for the different solution of electrolytes in water are given in Table-11.

The values of $\Delta \mathrm{S}^{*}$ for binary system obtained from the relation (15) are also recorded in Table-10. It is evidence from Table-10 that the values of $\Delta S^{*}$ are negative for the different solution of divalent transition metal sulphates and magnesium sulphate in water at $303.15 \mathrm{~K}$. The negative sign associated with $\Delta S^{*}$ shows that the hydrodynamic flow process, through the inorganic membrane of aluminum oxide has the strong electrostatic interactions between the wall of the pores of the membrane. This may be attributed to the state of high order during the transport process of the electrolytes in binary systems through the inorganic membrane of aluminum oxide.

The values of $\Delta \mathrm{H}^{*}$ and $\Delta \mathrm{S}^{*}$, thus calculated are related to $\Delta \mathrm{G}^{*}$ by the following relation:

$$
\Delta \mathrm{G}^{*}=\Delta \mathrm{H}^{*}-\mathrm{T} \Delta \mathrm{S}^{*}
$$

The values of $\Delta \mathrm{G}^{*}$ for the binary system calculated with help of relation (16) at $305.15 \mathrm{~K}$, have also recorded in Table-10. 


\begin{tabular}{|c|c|c|c|c|c|c|c|c|c|c|c|}
\hline \multicolumn{12}{|c|}{$\begin{array}{l}\text { TABLE-9 } \\
\text { VALUE OF } \log \text { L}_{P} \text { FOR DIFFERENT CONCENTRATIONS OF MANGANESE SULPHATE, COBALT SULPHATE, NICKEL SULPHATE, } \\
\text { COPPER SULPHATE, ZINC SULPHATE AND MAGNESIUM SULPHATE IN WATER AT DIFFERENT TEMPERATURES }\end{array}$} \\
\hline \multirow{2}{*}{$\begin{array}{c}\text { Conc. } \\
\text { (m) (mol } \\
\left.\mathrm{Kg}^{-1}\right)\end{array}$} & \multicolumn{5}{|c|}{$\log L_{P}$} & \multirow{2}{*}{$\begin{array}{c}\text { Conc. } \\
\text { (m) (mol } \\
\left.\mathrm{Kg}^{-1}\right)\end{array}$} & \multicolumn{5}{|c|}{$\log L_{P}$} \\
\hline & $298.15 \mathrm{~K}$ & $303.15 \mathrm{~K}$ & $308.15 \mathrm{~K}$ & $313.15 \mathrm{~K}$ & $318.15 \mathrm{~K}$ & & $298.15 \mathrm{~K}$ & $303.15 \mathrm{~K}$ & $308.15 \mathrm{~K}$ & $313.15 \mathrm{~K}$ & $318.15 \mathrm{~K}$ \\
\hline \multicolumn{6}{|c|}{ Manganese sulphate } & \multicolumn{6}{|c|}{ Copper sulphate } \\
\hline 0.001 & -8.570 & -8.547 & -8.530 & -8.517 & -8.494 & 0.001 & -8.628 & -8.583 & -8.568 & -8.538 & -8.508 \\
\hline 0.003 & -8.607 & -8.573 & -8.563 & -8.530 & -8.517 & 0.003 & -8.653 & -8.607 & -8.592 & -8.561 & -8.532 \\
\hline 0.005 & -8.638 & -8.588 & -8.585 & -8.557 & -8.536 & 0.005 & -8.677 & -8.628 & -8.614 & -8.580 & -8.561 \\
\hline 0.007 & -8.671 & -8.606 & -8.613 & -8.592 & -8.563 & 0.007 & -8.706 & -8.647 & -8.643 & -8.602 & -8.588 \\
\hline 0.010 & -8.708 & -8.626 & -8.642 & -8.621 & -8.588 & 0.010 & -8.741 & -8.656 & -8.669 & -8.628 & -8.618 \\
\hline 0.030 & -8.741 & -8.650 & -8.663 & -8.648 & -8.614 & 0.030 & -8.771 & -8.696 & -8.697 & -8.649 & -8.643 \\
\hline 0.050 & -8.784 & -8.676 & -8.678 & -8.777 & -8.630 & 0.050 & -8.787 & -8.714 & -8.729 & -8.684 & -8.668 \\
\hline \multicolumn{6}{|c|}{ Cobalt sulphate } & \multicolumn{6}{|c|}{ Zinc sulphate } \\
\hline 0.001 & -8.571 & -8.558 & -8.527 & -8.498 & -8.473 & 0.001 & -8.631 & -8.600 & -8.580 & -8.550 & -8.531 \\
\hline 0.003 & -8.600 & -8.606 & -8.558 & -8.530 & -8.508 & 0.003 & -8.662 & -8.630 & -8.607 & -8.578 & -8.558 \\
\hline 0.005 & 8.628 & -8.641 & -8.578 & -8.564 & -8.536 & 0.005 & -8.684 & -8.653 & -8.629 & -8.632 & -8.586 \\
\hline 0.007 & -8.659 & -8.567 & -8.598 & -8.623 & -8.598 & 0.007 & -8.710 & -8.671 & -8.649 & -8.632 & -8.619 \\
\hline 0.010 & -8.688 & -8.686 & -8.618 & -8.623 & -8.598 & 0.010 & -8.706 & -8.697 & -8.682 & -8.660 & -8.643 \\
\hline 0.030 & -8.722 & -8.708 & -8.647 & -8.650 & -8.629 & 0.030 & -8.760 & -8.713 & -8.703 & -8.685 & -8.665 \\
\hline 0.050 & -8.750 & -8.27 & -8.680 & -8.679 & -8.665 & 0.050 & -8.812 & -8.730 & -8.717 & -8.658 & -8.690 \\
\hline \multicolumn{6}{|c|}{ Nickel sulphate } & \multicolumn{6}{|c|}{ Magnesium sulphate } \\
\hline 0.001 & -8.649 & -8.630 & -8.622 & -8.547 & -8.526 & 0.001 & -8.650 & -8.593 & -8.588 & -8.562 & -8.539 \\
\hline 0.003 & -8.679 & -8.651 & -8.602 & -8.576 & -8.561 & 0.003 & -8.662 & -8.613 & -8.613 & -8.569 & -8.564 \\
\hline 0.005 & -8.710 & -8.671 & -8.628 & -8.604 & -8.588 & 0.005 & -8.695 & -8.630 & -8.537 & -8.623 & -8.583 \\
\hline 0.007 & -8.715 & -8.686 & -8.633 & -8.631 & -8.612 & 0.007 & -8.715 & -8.647 & -8.682 & -8.636 & -8.607 \\
\hline 0.010 & -8.765 & -8.704 & -8.691 & -8.653 & -8.635 & 0.010 & -8.745 & -8.667 & -8.701 & -8.666 & -8.631 \\
\hline 0.030 & -8.806 & -8.710 & -8.717 & -8.684 & -8.651 & 0.030 & -8.768 & -8.678 & -8.731 & -8.695 & -8.663 \\
\hline 0.050 & -8.877 & -8.746 & -8.713 & -8.721 & -8.689 & 0.050 & -8.000 & -8.688 & -8.768 & -8.713 & -8.701 \\
\hline
\end{tabular}

TABLE-10

VALUES OF THE ACTIVATION PARAMETERS $\left(\Delta H^{*}, \Delta \mathrm{S}^{*}\right.$ AND $\left.\Delta \mathrm{G}^{*}\right)$ FOR MANGANESE SULPHATE, COBALT SULPHATE, NICKEL SULPHATE, COPPER SULPHATE, ZINC SULPHATE AND MAGNESIUM SULPHATE IN WATER

\begin{tabular}{|c|c|c|c|c|c|c|c|}
\hline $\begin{array}{l}\text { Conc. }(\mathrm{m}) \\
(\mathrm{mol} \mathrm{Kg}\end{array}$ & $\begin{array}{l}\Delta \mathrm{H}^{*} \times 10^{3} \\
\left(\mathrm{KJ} \mathrm{mol}^{-1}\right)\end{array}$ & $\begin{array}{c}\Delta \mathrm{S}_{303.15 \mathrm{~K}}^{*} \times 10^{3} \\
\left(\mathrm{KJ} \mathrm{mol}^{-1}\right)\end{array}$ & $\begin{array}{l}\Delta \mathrm{G}_{303.15 \mathrm{~K}}^{*} \\
\left(\mathrm{KJ} \mathrm{mol}^{-1}\right)\end{array}$ & $\begin{array}{l}\text { Conc. (m) } \\
\left(\mathrm{mol} \mathrm{Kg}^{-1}\right)\end{array}$ & $\begin{array}{l}\Delta \mathrm{H}^{*} \times 10^{3} \\
\left(\mathrm{KJ} \mathrm{mol}^{-1}\right)\end{array}$ & $\begin{array}{c}\Delta \mathrm{S}_{303.15 \mathrm{~K}}^{*} \times 10^{3} \\
\left(\mathrm{KJ} \mathrm{mol}^{-1}\right)\end{array}$ & $\begin{array}{l}\Delta \mathrm{G}^{*} \\
\left(\mathrm{KJ} \mathrm{mol}^{-1}\right) \\
\end{array}$ \\
\hline \multicolumn{4}{|c|}{ Manganese sulphate } & \multicolumn{4}{|c|}{ Copper sulphate } \\
\hline 0.001 & -0.342 & -22.202 & 6.730 & 0.001 & -0.536 & -24.254 & 7.352 \\
\hline 0.003 & -0.416 & -22.452 & 6.806 & 0.003 & -0.542 & -24.280 & 7.360 \\
\hline 0.005 & -0.442 & -22.460 & 6.808 & 0.005 & -0.527 & -24.237 & 7.347 \\
\hline 0.007 & -0.435 & -22.528 & 6.829 & 0.007 & -0.529 & -24.248 & 7.350 \\
\hline 0.010 & -0.458 & -22.613 & 6.854 & 0.010 & -0.515 & -24.199 & 7.335 \\
\hline 0.030 & -0.477 & -22.718 & 6.886 & 0.030 & -0.571 & -24.426 & 7.404 \\
\hline 0.050 & -0.570 & -23.056 & 6.989 & 0.050 & -0.505 & -24.239 & 7.348 \\
\hline \multicolumn{4}{|c|}{ Cobalt sulphate } & \multicolumn{4}{|c|}{ Zinc sulphate } \\
\hline 0.001 & -0.483 & -25.309 & 7.672 & 0.001 & -0.471 & -24.548 & 7.441 \\
\hline 0.003 & -0.491 & -25.342 & 7.682 & 0.003 & -0.341 & -24.126 & 7.313 \\
\hline 0.005 & -0.492 & -25.352 & 7.685 & 0.005 & -0.480 & -24.592 & 7.454 \\
\hline 0.007 & -0.467 & -25.276 & 7.662 & 0.007 & -0.414 & -24.380 & 7.390 \\
\hline 0.010 & -0.454 & -25.242 & 7.652 & 0.010 & -0.308 & -24.039 & 7.287 \\
\hline 0.030 & -0.457 & -25.293 & 7.667 & 0.030 & -0.389 & -24.348 & 7.381 \\
\hline 0.050 & -0.430 & -25.234 & 7.649 & 0.050 & -0.595 & -24.059 & 7.596 \\
\hline \multicolumn{4}{|c|}{ Nickel sulphate } & \multicolumn{4}{|c|}{ Magnesium sulphate } \\
\hline 0.001 & -0.626 & -24.735 & 7.503 & 0.001 & -0.475 & -23.998 & 7.274 \\
\hline 0.003 & -0.585 & -24.606 & 7.460 & 0.003 & -0.453 & -23.932 & 7.254 \\
\hline 0.005 & -0.584 & -24.608 & 7.459 & 0.005 & -0.432 & -23.869 & 7.235 \\
\hline 0.007 & -0.487 & -24.294 & 7.364 & 0.007 & -0.429 & -23.869 & 7.234 \\
\hline 0.010 & -0.584 & -24.622 & 7.463 & 0.010 & -0.431 & -23.881 & 7.239 \\
\hline 0.030 & -0.629 & -24.804 & 7.518 & 0.030 & -0.554 & -24.328 & 7.374 \\
\hline 0.050 & -0.538 & -24.529 & 7.434 & 0.050 & -0.326 & -23.609 & 7.156 \\
\hline
\end{tabular}


TOR MANGANESE SULPHATE, COBALT SULPHATE, NICKEL SULPHATE, COPPER SULPHATE, ZINC SULPHATE AND MAGNESIUM SULPHATE IN WATER AT 303.15 K

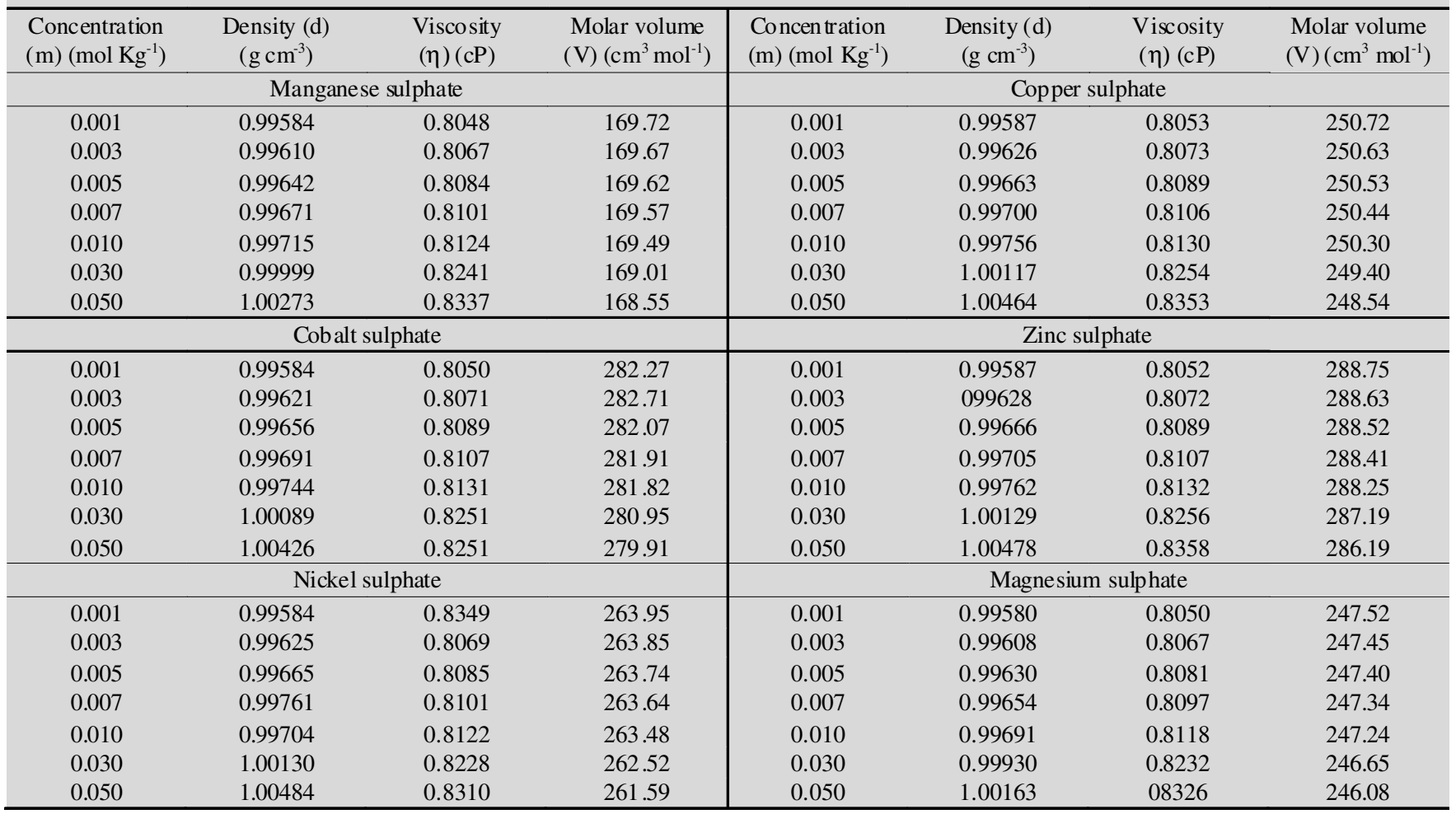

It is now cleared from Table-10 that the value of $\Delta \mathrm{G}^{*}$ are positive for binary system (mentioned above) at $303.15 \mathrm{~K}$, thereby suggesting that the flow is not favoured across the inorganic membrane of aluminum oxide i.e. flow is nonspontaneous. In order words, it may be said that until an input force is applied across the inorganic membrane of aluminum oxide, the flow of permitting fluid cannot take place.

\section{REFERENCES}

\section{G. Quinke, Pogg. Ann., 107, 1 (1859).}

2. H.R. Kruyt, Kolloid Z., 22, 81 (1918); https://doi.org/10.1007/BF01459626.

3. H. Freundlich and E. Rona, Sitzber. Preuss. Akad. Wiss. Physik. Math $K l ., 20,397$ (1920)

4. H.R. Kruyt and P.C. Willigen, Kolloid Z., 45, 307 (1928); https://doi.org/10.1007/BF01423428.

5. E.F. Burton, Phil. Mag., 11, 425 (1906);

6. A. Tiselius, Kolloid Z., 85, 129 (1938); https://doi.org/10.1007/BF01519260.

7. M.V. Smoluchowaski, in Graetz, Hand buck der Elebtriztat abd des Magbetisus II, Liepzig, p. 336 (1921).

8. P.J.W. Debye and E.A.A. Huckel, J. Phys., 24, 135 (1933).

9. R. Dom, W. Ann, 10, 46 (1980).

10. B. Salopek, D. Krasi and S. Filipovi, Rudarsko-geoloiko-naftni zbornik, 4, 147(1992)

11. J.D. Quist and E.R. Washburn, J. Am. Chem. Soc., 62, 3169 (1940); https://doi.org/10.1021/ja01868a076

12. J. Reuss, Mem Soc. Imp Naturalists Moscow, 2, 327 (1809).

13. G. Wiedemann, Pogg. Ann, 99, 177 (1857).

14. H.C. Hepburn, Proc. Phys. Soc. Lond., 39, 99 (1927).

15. H.V. Helmholtz, W. Ann, 243, 337 (1879); https://doi.org/10.1002/andp.18792430702

16. H. Lamb, Philos. Mag., 25, 52 (1888); https://doi.org/10.1080/14786448808628148
17. R.P. Rastogi, Introduction to Non-Equilibrium Physical Chemistry, Elsevier, edn 1 (2008).

18. N. Lakshminarayanaiah, Chem. Rev., 65, 493 (1965); https://doi.org/10.1021/cr60237a001.

19. N. Lakshminarayaniah, Transport Phenomena in Membranes, Academic Press Inc., New York, p. 6 (1969).

20. K.S. Spiegler, Farady Soc., 54, 1408 (1958); https://doi.org/10.1039/tf9585401408

21. R.L. Blokhra, S.K. Agarwal and N. Arora, J. Colloid Int. Sci., 73, 88 (1980); https://doi.org/10.1016/0021-9797(80)90125-3.

22. R.L. Blokhra and S. Kohli, J. Non-Equilib. Thermodyn., 5, 205 (1980); https://doi.org/10.1515/jnet.1980.5.4.205.

23. R.L. Blokhra, M.L. Parmar and R. Sidhu, J. Non-Equilib. Thermodyn., 8, $183(1983)$ https://doi.org/10.1515/jnet.1983.8.3.183

24. R.L. Blokhra and S. Kohli, J. Electroanal. Chem. Interfacial Electrochem., 124, 285 (1981); https://doi.org/10.1016/S0022-0728(81)80305-1.

25. R.L. Blokhra, S.C. Chauhan and R. Sidhu, J. Indian Chem. Soc., 59, 63 (1982).

26. R.L. Blokhra, M.L. Parmar and S.C. Chauhan, J. Membr. Sci., 14, 67 (1983); https://doi.org/10.1016/S0376-7388(00)81374-5.

27. R. Thakur, R. Sharma and B. Saini, Asian J. Chem., 28, 2043 (2016); https://doi.org/10.14233/ajchem.2016.19889.

28. K. Singh, R. Kumar and V.N. Srivastava, J. Indian Chem. Soc., 57, 203 (1980).

29. R.P. Rastogi, K. Singh and M.L. Srivastava, J. Phys. Chem., 73, 46 (1969); https://doi.org/10.1021/j100721a008.

30. B.Z. Ginzburg and A. Katachalsky, J. Gen. Physiol., 47, 403 (1963); https://doi.org/10.1085/jgp.47.2.403.

31. A.J. Staverman, Roc. Trav. Chim, 70, 344 (1951); https://doi.org/10.1002/recl.19510700409.

32. S. Hwang and K. Kemmermeyer, Techniques of Chemistry, Membranes in Separations, John Wiley, New York, vol. 8, p. 133 (1975).

33. S. Glastone, K.J. Laidler and H. Eyring, Theory of Rate Processes, McGraw Hill, New York (1941). 